\title{
PHYTOCHEMICAL ANALYSIS OF ALKALOIDS FROM THE CHILEAN ENDEMIC TREE CRYPTOCARYA ALBA
}

\author{
SEBASTIÁN CASTRO-SAAVEDRA ${ }^{1,2}$, GONZALO FUENTES-BARROS ${ }^{1,2}$, \\ CRISTIAN TIRAPEGUI ${ }^{2}$,WILLIAMS ACEVEDO-FUENTES ${ }^{2}$, BRUCE K. CASSELS ${ }^{2}$, \\ ANDRÉS BARRIGA ${ }^{3}$, MARCELO VILCHES-HERRERA ${ }^{2, *}$.
}

\author{
${ }^{1}$ School of Forestry Engineering, Universidad Mayor, Santiago, Chile \\ ${ }^{2}$ Department of Chemistry, Faculty of Sciences, University of Chile, Santiago, Chile \\ ${ }^{3}$ CEPEDEQ, Faculty of Chemical and Pharmaceutical Sciences, University of Chile, Santiago, Chile \\ *Corresponding author. Faculty of Sciences, Department of Chemistry, University of Chile. \\ Las Palmeras 3425, Ñuñoa, Santiago 7800024, Chile. (M. Vilches-Herrera).
}

\begin{abstract}
A phytochemical study of the roots and aerial parts of Cryptocarya alba (Mol.) Looser (Lauraceae), an endemic Chilean tree and the southernmost Cryptocarya species, led for the first time to the isolation and unambiguous characterization of four known alkaloids by NMR techniques: boldine, laurolitsine, laurotetanine and norglaucine, in addition to the previously identified reticuline, and the identification via UHPLC-MS of seven more alkaloids, coclaurine, $N$-methylcoclaurine, norreticuline, isocorydine, $N$-methyllaurotetanine, predicentrine and glaucine. In spite of this fairly broad variety of benzyltetrahydroisoquinolines and aporphines, the concentrations of these alkaloids in the different organs of $C$. alba are quite low, which is in contrast with the sometimes generous yields of alkaloids in this genus.
\end{abstract}

\section{INTRODUCTION}

Cryptocarya alba (Mol.) Looser (vernacular name peumo, penu, pegu or pengu in the Mapuche language), one of the four or five endemic Chilean Lauraceae, is an evergreen shade- and frost-tolerant tree that grows up to $1500 \mathrm{~m}$ above sea level, distributed from about 30 to $40{ }^{\circ} \mathrm{S},{ }^{1}$ spanning the Mediterranean climate zone of Chile and the north of the rainier temperate zone. It is therefore the southernmost representative of its pantropical genus which consists of about 350 species, ${ }^{2}$ and it has been isolated from its South American congeners since the mid-Pliocene (about 3.5 million years ago) by the 'arid diagonal' established at that time due to the final raising of the Andean range. ${ }^{3}$ It is amongst the most abundant native trees in Central Chile, and one of the dominant species of the sclerophyllous forest along with Peumus boldus Mol. (Monimiaceae), Lithraea caustica Mol. (Anacardiaceae) and Quillaja saponaria Mol. (Quillajaceae). Due to its exceptional concentration of endemic species, this region has been identified as one of the world's 25 biodiversity hotspots. ${ }^{4} \mathrm{C}$. alba is a threatened species due to overexploitation and habitat destruction, ${ }^{1}$ and is considered vulnerable in some areas of central Chile and exceptional in the southern part of its range. ${ }^{2}$ It is well known for its oblong, pink to red, intensely aromatic edible fruits (peumos), the thin pericarp of which has been consumed by the local peoples since before the arrival of Europeans. Peumos are also food for birds, foxes and rodents. ${ }^{5}$ The oleaginous seeds may have been chewed and made into an alcoholic beverage, or cooked and eaten "in times of scarcity". ${ }^{6}$ However the ethnopharmacology of C. alba is somewhat ambiguous and its chemical composition is almost unknown. Its reported uses in folk medicine include the infusion of its bark for the treatment of liver diseases, the infusion of leaves and bark against rheumatism and to heal wounds, and an ointment made from the ground seeds to treat vaginal infections. ${ }^{7}$ Regarding its phytochemistry, the presence of tannin and resins in the leaves, bark and fruits was reported by Gautier half a century ago. ${ }^{8}$ The composition and antimicrobial effect of the essential oil distilled from the very aromatic leaves has also been investigated by at least three independent groups, and is composed mainly of monoterpenoids such as terpin-1-en-4-ol, $\beta$-terpinene, 1,8-cineole (eucalyptol), p-cymene, $\alpha$ - and $\beta$-pinene., ${ }^{9,11}, 11$ Ten flavonoids and chlorogenic acid were isolated and identified from the leaves and stem in $1995,{ }^{12}$ and much more recently 19 phenolic compounds, mainly flavonoids and phenolic acids, were identified in the fruits and aerial parts, and the antioxidant activity of their methanol extracts was assayed. ${ }^{13}$ The ripe fruits contain the $\alpha$-pyrones cryptofolione and 6-(4,6-dimethoxy-8-phenylocta-1,7dienyl)-4-hydroxytetrahydropyran-2-one. Cryptofolione and its acetate were shown to be moderately cytotoxic and active against Trypanosoma cruzi and Leishmania species. ${ }^{14}$

Considering that Lauraceae are often rich sources of alkaloids and that a fair number of Cryptocarya species have been shown to contain structurally diverse isoquinoline alkaloids, ${ }^{15}$ it is somewhat surprising that the benzyltetrahydroisoquinoline $(+)(S)$-reticuline is the only alkaloid reported from the stem bark and leaves of this species. ${ }^{16}$ In the framework of a chemical investigation of sclerophyllous forest trees of Central Chile, we therefore undertook a meticulous study of the alkaloids present in C. alba including the root, leaves, bark and wood in order to characterize the composition at different growth stages, and to obtain data that might contribute to explain, in an evolutionary context, the events associated with the isolation of this species from its geographically closest Southern Brazilian and Northern Peruvian relatives. We also expected to find some support for the various uses of this species in traditional medicine. This work led for the first time to the isolation and characterization by NMR techniques of four alkaloids aside from reticuline, and the identification via UHPLC-MS of seven additional alkaloids.

\section{EXPERIMENTAL}

Plant material (leaves, wood, bark and root) of a single Cryptocarya alba tree growing near Ibacache $\left(33^{\circ} 26^{\prime} \mathrm{S}, 71^{\circ} 18^{\prime} \mathrm{W}, 230 \mathrm{~m}\right.$ above sea level), Chile, in May 2014 (southern autumn), was used for isolation of the major alkaloids. In addition, samples were collected from 12 young adult individuals belonging to the same population, with diameter at breast height (DBH) less than $10 \mathrm{~cm}$; seven larger trees with $\mathrm{DBH}>30 \mathrm{~cm}$ were sampled in La Aurora ( $33^{\circ} 22^{\prime}$ S, $70^{\circ} 58^{\prime}$ W. $950 \mathrm{~m}$ above sea level), Chile, and seven saplings less that 3 years old from a commercial tree farm near Los Ángeles, Chile, grown under controlled conditions, were analyzed for comparison.

\subsection{Reference Standards}

$(S)$-Glaucine and $(S)$-predicentrine were prepared from boldine by methylation with diazomethane..$^{17}(R S)$-Norreticuline was synthesized by the Bischler-Napieralski route. ${ }^{18}$ Isocorydine $\mathrm{HCl}$ was purchased from PhytoLab GmbH \& Co. (Vestenbergsgreuth, Bavaria, Germany).

\subsection{Extraction}

Leaves were dried at $40{ }^{\circ} \mathrm{C}$ during $72 \mathrm{~h}(3.5 \mathrm{~kg})$, then were milled directly, whilst bark $(3.5 \mathrm{~kg})$, wood $(5.0 \mathrm{~kg})$ and roots $(4.0 \mathrm{~kg})$ were dried similarly and ground using first a chipper and then a mill. Each $\mathrm{kg}$ of material was macerated and extracted three times with $10 \mathrm{~L}$ of methanol $(\mathrm{MeOH})$ at $50{ }^{\circ} \mathrm{C}$ for 12 hours. The extracts were filtered off, concentrated, the residues taken up in dichloromethane (DCM) and extracted three times with an equal volume of dilute hydrochloric acid (approximately $1 \mathrm{~mol} / \mathrm{L}$ ). The aqueous solution was extracted successively with hexane and ethyl acetate, and then made basic $(\mathrm{pH}$ 10) using concentrated aqueous ammonia solution $(25 \%)$ and extracted with DCM. The organic extract was dried over sodium sulfate, filtered and stripped of the solvent under reduced pressure. For the chromatographic quantifications the same procedure was followed, starting from $1 \mathrm{~g}$ dried and ground plant material. 
2.3 Isolation and Purification

Each crude alkaloid fraction, namely, $100 \mathrm{mg}$ from leaves, 2,00 $\mathrm{g}$ from bark, $450 \mathrm{mg}$ from wood, and 1,00 $\mathrm{g}$ from roots was placed on a silica gel 60 $\AA(40-63 \mu \mathrm{m})$ Sigma-Aldrich ${ }^{\circledR}$ column $(30 \times 3,30 \times 7,30 \times 3$, and $30 \times 5 \mathrm{~cm}$, respectively) and was eluted with ethyl acetate (EtOAc) gradually enriched with methanol $(\mathrm{MeOH})$, specifically as follows: $100 \% \mathrm{EtOAc}, \mathrm{EtOAc} / \mathrm{MeOH}$ 4:1, EtOAc/MeOH 2:1, EtOAc/MeOH 1:1 and $\mathrm{MeOH} 100 \% .20 \mathrm{~mL}$ fractions were collected, spotted on silica gel chromatofoils (Merck $\mathrm{F}_{254} 20$ × $20 \mathrm{~cm}$; (mobile phase EtOAc 100\%, EtOAc/MeOH 4:1 and DCM/MeOH 5:3), the aromatic compounds detected by UV light (254 and $366 \mathrm{~nm}$ ) and the alkaloids visualized with Dragendorff reagent.

2.4 Structural Identification

Identification of the individual compounds was done by ${ }^{1} \mathrm{H}$ and ${ }^{13} \mathrm{C}$ NMR and/or by UHPLC-MS by comparison with standards. NMR spectra were

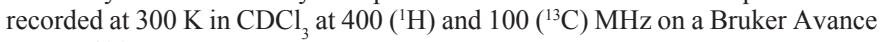
III HD $400 \mathrm{MHz}$ spectrometer.

\subsubsection{Liquid Chromatography and Mass Spectrometry}

The samples were injected $(10 \mu \mathrm{L})$ onto a PhenomenexSynergi RP $80 \AA$ ( $50 \mathrm{~mm}$ x $2.0 \mathrm{~mm}, 4 \mu \mathrm{m})$ column mounted in an ultra-high pressure Eksigent liquid chromatograph, model EkspertUltraLC 100-XL, coupled to a triple quadrupole mass spectrometer operating in the electrospray (ESI) mode (ABSciex Triple Quad 4500 (LC-MS/MS)). The mobile phase was composed of aqueous formic acid $0.1 \% \mathrm{v} / \mathrm{v}$ (eluent A) and acetonitrile (eluent B) at a flow rate of $0.3 \mathrm{~mL} / \mathrm{min}$ with the following concentration gradient program: (time, $\min / \%$ eluent B) $0 / 3,3 / 3,13 / 15,16 / 20,17 / 3$ and 18/3, adapted from Zeng et al., 2015..$^{19}$ The mass spectrometer parameters were: GS1 nitrogen (40 psi); GS2 nitrogen (50 psi); IS, $3500 \mathrm{~V}$, temperature $650{ }^{\circ} \mathrm{C}$; CURT nitrogen $(25$ psi); Flow $0,3 \mathrm{~mL} / \mathrm{min}$. scan mode MRM, positive polarity positive. The LCMS/MS system was controlled by Analyst 1.6.2 and the data were processed using Multiquant software version 3.0. Calibration curves were built for each compound in the $0.01-1 \mathrm{mg} / \mathrm{mL}$ range, for which the following equations were obtained: laurolitsine $y=3.7 \times 10^{7} x+2.2 \times 10^{6}, \mathrm{R}^{2}=0.993$; boldine $y=1.0 \times$ $10^{8} x+1.6 \times 10^{7}, \mathrm{R}^{2}=0.979 ;$ reticuline $y=1.0 \times 10^{8} x+1.2 \times 10^{7}, \mathrm{R}^{2}=0.979 ;$ laurotetanine $\mathrm{y}=4.7 \times 10^{7} x+1.9 \times 10^{5}, \mathrm{R}^{2}=0.996$; predicentrine $y=7.2 \times 10^{7} x$ $+1.4 \times 10^{6}, \mathrm{R}^{2}=0.994$; isocorydine: $y=9.1 \times 10^{7} x+4.1 \times 10^{6}, \mathrm{R}^{2}=0.996$; norglaucine $y=8.0 \times 10^{7} x+2.7 \times 10^{6}, \mathrm{R}^{2}=0.994 ; N$-methyllaurotetanine $y=$ $\left.1.0 \times 10^{7} x+8,9 \times 10^{5}, \mathrm{R}^{2}=0.988\right)$. Results were expressed as $\mathrm{mg}$ of alkaloid $/ \mathrm{g}$ dry weight (mg/g DW).

\section{RESULTS AND DISCUSSION}

The leaves, bark, wood and roots of C. alba yielded $100 \mathrm{mg}(0.003$ $\%), 2.00 \mathrm{~g}(0.057 \%), 450 \mathrm{mg}(0.009 \%)$ and $1.00 \mathrm{~g}(0.025 \%)$ of crude alkaloids, respectively. Twelve alkaloids were identified in all: four benzyltetrahydroisoquinolines: reticuline, coclaurine, $N$-methylcoclaurine and norreticuline; and eight aporphines: boldine, isocorydine, laurolitsine, laurotetanine, $N$-methyllaurotetanine, predicentrine, norglaucine and glaucine. Benzylisoquinolines and aporphines are the most widespread alkaloids in the Lauraceae, ${ }^{15}$ and are commonly found in Cryptocarya species. ${ }^{20,21,22,23,24}$. Alkaloids present in very small amounts insufficient for NMR analysis were identified based on their MS fragmentation patterns compared with those reported in the literature or obtained with authentic samples (Table 1).

Table 1. Retention times, molecular and characteristic fragment ions, and occurrence of alkaloids identified in C. alba.

\begin{tabular}{|c|c|c|c|c|}
\hline Compounds & $\begin{array}{l}\text { Retention } \\
\text { time (min.) }\end{array}$ & $\begin{array}{l}{[\mathrm{M}+\mathrm{H}]^{+}} \\
\text {found (calc.) }\end{array}$ & Characteristic $\mathrm{MS}^{2}$ ion fragments $\mathrm{m} / \mathrm{z}$ (\% rel. abund.) & Occurrence \\
\hline Coclaurine & 5.90 & $\begin{array}{c}285.953 \\
(286.144)\end{array}$ & $\begin{array}{c}181.0(5.9), 189.1(10.4), 193.9(18.0), 209.1(34.8), 209.2 \\
(16.9), 237.0(28.6), 269.1(100)\end{array}$ & $\mathrm{L}, \mathrm{W}, \mathrm{B}, \mathrm{R}$ \\
\hline$N$-Me-Coclaurine & 6.15 & $\begin{array}{l}299.976 \\
(300.160)\end{array}$ & $\begin{array}{c}181.2(2.7), 189.0(10.4), 192.0(27.4), 209.1(20.7), 237.1 \\
(20.0), 269.0(100)\end{array}$ & $\mathrm{R}, \mathrm{W}, \mathrm{B}$ \\
\hline Norreticuline & 6.78 & $\begin{array}{l}316.037 \\
(316.155)\end{array}$ & $\begin{aligned} & 151.0(2.6), 152.2(6.3), 163.1(25.7), 165.0(5.3), 175.1 \\
&(16.3), 178.0(100), 299(37.3)\end{aligned}$ & $\mathrm{R}$ \\
\hline Laurolitsine & 6.85 & $\begin{array}{l}314.070 \\
(314.139)\end{array}$ & $\begin{array}{c}165.1(51.1), 176.1(15.3), 194.0(35.9), 205.1(29.2), \\
237.1(54.3), 264.9(100), 297.1(90.2)\end{array}$ & L, W, B \\
\hline Boldine & 7.40 & $\begin{array}{c}327.964 \\
(328.155)\end{array}$ & $\begin{array}{c}194.0(33.1), 205.0(32.7), 221.9(26.4), 237.1(57.1), \\
264.9(100), 282.0(49.8), 297.0(82.9)\end{array}$ & $\mathrm{L}, \mathrm{W}, \mathrm{B}, \mathrm{R}$ \\
\hline Reticuline & 7.90 & $\begin{array}{c}330.033 \\
(330.171)\end{array}$ & $\begin{array}{c}151.1(5.9), 152.0(7.0), 165.1(3.5), 175.1(29.5), 177.1 \\
(30.0), 178.1(7.1), 192.1(100)\end{array}$ & $\mathrm{L}, \mathrm{W}, \mathrm{B}, \mathrm{R}$ \\
\hline Laurotetanine & 9.50 & $\begin{array}{l}328.024 \\
(328.155)\end{array}$ & $\begin{array}{c}194.0(22.0), 205.1(79.7), 236.9(37.6), 264.9(44.6), \\
280.0(55.7), 296.0(36.1), 310.9(100)\end{array}$ & L, W, B \\
\hline Predicentrine & 9.68 & $\begin{array}{c}342.033 \\
(342.171)\end{array}$ & $\begin{array}{c}189.2(17.5), 194.0(16.6), 204.9(18.0), 207.2(23.9), \\
251.1(55.1), 265.0(28.5), 279.0(100)\end{array}$ & $\mathrm{R}, \mathrm{W}, \mathrm{B}$ \\
\hline Isocorydine & 10.50 & $\begin{array}{c}342.071 \\
(342.171)\end{array}$ & $\begin{array}{c}152.1(26.4), 163.1(21.7), 165.0(45.7), 178.0(22.8), \\
189.1(29.0), 278.9(100), 311.0(71.1)\end{array}$ & $\mathrm{L}, \mathrm{W}, \mathrm{B}, \mathrm{R}$ \\
\hline Norglaucine & 11.80 & $\begin{array}{c}341.870 \\
(342.171)\end{array}$ & $\begin{array}{c}194.2(86.0), 205.0(53.3), 222.1(57.6), 236.9(97.8), \\
248.1(6.1), 265.0(100), 279.9(44.1)\end{array}$ & $\mathrm{L}, \mathrm{W}, \mathrm{B}, \mathrm{R}$ \\
\hline$N$-Me-laurotetanine & 12.10 & $\begin{array}{c}342.055 \\
(342.171)\end{array}$ & $\begin{array}{c}194.0(22.2), 237.1(45.2), 265.0(45.0), 280.0(75.5), \\
281.0(37.9), 296.0(38.5), 311.1(100)\end{array}$ & $\mathrm{L}, \mathrm{W}, \mathrm{B}, \mathrm{R}$ \\
\hline Glaucine & 14.61 & $\begin{array}{c}356.091 \\
(356.187)\end{array}$ & $\begin{array}{c}189.1(20.7), 251.1(21.6), 279.0(50.9), 294.0(100), \\
295.0(41.3), 310.0(55.3), 325.2(86.9)\end{array}$ & $\mathrm{L}, \mathrm{W}, \mathrm{B}, \mathrm{R}$ \\
\hline
\end{tabular}

Abbreviations: R: roots; L: leaves; W: wood; B: bark.

The characteristic ${ }^{1} \mathrm{H}$ and ${ }^{13} \mathrm{C}$ NMR assignments are collected in Tables 2 and 3, respectively. When the amount of sample was enough to record ${ }^{13} \mathrm{C}-\mathrm{NMR}$ spectra these were obtained and, the characteristic assignments are reported in Table 2. The NMR data are in general agreement with those recorded in the literature. ${ }^{20,21,22,23,24}$ The numbering of each kind of structure is shown in Figure 1. 


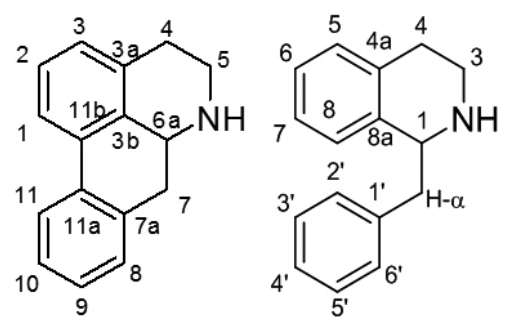

Figure 1. Numbering used for aporphines (left) and tetrahydroisoquinolines (right).

Table 2. ${ }^{1} \mathrm{H}$ data $\left(\mathrm{CDCl}_{3}\right)$ for the isolated alkaloids from C. alba.

\begin{tabular}{|c|c|c|c|c|c|c|}
\hline${ }^{1} \mathbf{H}^{\mathbf{a}}$ & Boldine & Laurolitsine & Laurotetanine & Norglaucine & ${ }^{{ }^{1} \mathbf{H}^{\mathbf{b}}}$ & Reticuline \\
\hline $\mathrm{H}-3$ & $6.64(\mathrm{~s})$ & $6.63(\mathrm{~s})$ & $6.59(\mathrm{~s})$ & $6.60(\mathrm{~s})$ & $\mathrm{H}-5$ & $6.53(\mathrm{~s})$ \\
\hline $\mathrm{H}-8$ & $6.83(\mathrm{~s})$ & $6.78(\mathrm{~s})$ & $6.76(\mathrm{~s})$ & $6.80(\mathrm{~s})$ & $\mathrm{H}-8$ & $6.34(\mathrm{~s})$ \\
\hline $\mathrm{H}-11$ & $7.89(\mathrm{~s})$ & $7.91(\mathrm{~s})$ & $8.07(\mathrm{~s})$ & $8.07(\mathrm{~s})$ & $\mathrm{H}-5^{\prime}$ & $6.72(\mathrm{dd}, J=8.2,1.8 \mathrm{~Hz})$ \\
\hline $\mathrm{MeO}-1$ & $3.60(\mathrm{~s})$ & $3.57(\mathrm{~s})$ & $3.66(\mathrm{~s})$ & $3.66(\mathrm{~s})$ & $\mathrm{H}-2^{\prime}$ & $6.74(\mathrm{~d}, 1.9 \mathrm{~Hz})$ \\
\hline $\mathrm{MeO}-2$ & - & - & $3.88(\mathrm{~s})$ & $3.89(\mathrm{~s})^{*}$ & $\mathrm{H}-6^{\prime}$ & $6.57(\mathrm{~d}, J=8.2 \mathrm{~Hz})$ \\
\hline $\mathrm{MeO}-9$ & - & - & - & $3.90(\mathrm{~s})^{*}$ & $\mathrm{MeO}-6$ & $3.83^{*}(\mathrm{~s})$ \\
\hline $\mathrm{MeO}-10$ & $3.91(\mathrm{~s})$ & $3.77(\mathrm{~s})$ & $3.88(\mathrm{~s})$ & $3.91(\mathrm{~s})^{*}$ & $\mathrm{MeO}-4$ & $3.83^{*}(\mathrm{~s})$ \\
\hline
\end{tabular}

*Interchangeable assignments, aporphines, ${ }^{b}$ tetrahydroisoquinolines

Table 3. ${ }^{13} \mathrm{C}$ NMR data $\left(\mathrm{CDCl}_{3}\right)$ for isolated alkaloids from C. alba.

\begin{tabular}{|c|c|c|c|c|c|c|}
\hline${ }^{13} \mathrm{C}^{\mathrm{a}}$ & Boldine & Laurolitsine & Laurotetanine & Norglaucine & ${ }^{13} \mathbf{C}^{\mathrm{b}}$ & Reticuline \\
\hline $\mathrm{C}-1$ & 142.2 & 142.7 & 144.3 & 144.7 & C-4' & 145.5 \\
\hline $\mathrm{C}-2$ & 148.3 & 149.4 & 155.2 & 152.8 & C-3' & 145.4 \\
\hline $\mathrm{C}-3$ & 113.3 & 114.6 & 110.9 & 110.8 & C-6 & 145.3 \\
\hline C-3a & 129.8 & 128.8 & 129.1 & 125.4 & $\mathrm{C}-7$ & 143.6 \\
\hline$C-3 b$ & 125.9 & 125.5 & 126.9 & 123.2 & $\mathrm{C}-1^{\prime}$ & 133.0 \\
\hline $\mathrm{C}-4$ & 28.4 & 27.9 & 29.2 & 29.8 & $\mathrm{C}-4 \mathrm{a}$ & 129.9 \\
\hline $\mathrm{C}-5$ & 53.2 & 42.2 & 43.2 & 42.5 & C-8a & 125.0 \\
\hline C-6a & 62.5 & 53.2 & 53.8 & 53.1 & C-6' & 121.0 \\
\hline $\mathrm{C}-7$ & 33.8 & 35.5 & 36.7 & 32.1 & $\mathrm{C}-2$ & 115.8 \\
\hline$C-7 a$ & 129.5 & 129.1 & 129.9 & 125.2 & $\mathrm{C}-8$ & 113.9 \\
\hline $\mathrm{C}-8$ & 114.3 & 115.1 & 114.3 & 114.2 & $\mathrm{C}-5$ & 110.8 \\
\hline C-9 & 145.2 & 145.9 & 145.2 & 145.3 & $\mathrm{C}-5$ & 110.7 \\
\hline $\mathrm{C}-10$ & 145.7 & 146.1 & 145.6 & 145.7 & $\mathrm{C}-1$ & 64.6 \\
\hline $\mathrm{C}-11$ & 110.2 & 112.1 & 111.5 & 111.5 & $\mathrm{MeO}-6$ & 56.0 \\
\hline C-11a & 123.5 & 122.9 & 123.9 & 122.9 & $\mathrm{MeO}-4$ & 55.9 \\
\hline $\mathrm{C}-11 \mathrm{~b}$ & 126.8 & 125.9 & 128.2 & 123.6 & $\mathrm{C}-3$ & 46.8 \\
\hline MeO-1 & 60.3 & 59.3 & 60.2 & 60.3 & $N$-Me & 42.4 \\
\hline $\mathrm{MeO}-2$ & - & - & 56.1 & 56.3 & $C-\alpha$ & 41.0 \\
\hline MeO-9 & - & - & - & 56.2 & $\mathrm{C}-4$ & 24.9 \\
\hline MeO-10 & 56.2 & 55.7 & 55.9 & 56.0 & - & - \\
\hline MeN-6 & 43.5 & - & - & - & - & - \\
\hline
\end{tabular}

${ }^{a}$ aporphines, ${ }^{b}$ tetrahydroisoquinolines

Table 4 shows the concentration ranges of the alkaloids identified in the different organs of $C$. alba individuals of different ages. Coclaurine, $N$-methylcoclaurine, and norreticuline were not found in our samples. Traces of glaucine were present in the leaves and bark of some of the older trees. 
Table 4. Concentration of alkaloids in Cryptocarya alba biomass (mg/g DW).

\begin{tabular}{|c|c|c|c|c|c|c|c|}
\hline & \multirow{2}{*}{\multicolumn{2}{|c|}{$\begin{array}{cc}\text { Saplings } & <3 \text { years } \\
\mathrm{n}=7 & \mathrm{n}=7\end{array}$}} & \multicolumn{3}{|c|}{ Trees DBH $<10 \mathrm{~cm}$} & \multicolumn{2}{|c|}{ Trees $\mathrm{DBH}>30 \mathrm{~cm}$} \\
\hline & & & $\mathrm{n}=$ & $\mathrm{n}=12$ & $n=12$ & $\mathrm{n}=7$ & $\mathrm{n}=7$ \\
\hline & Leaves & Stems & Leaves & Wood & Bark & Leaves & Bark \\
\hline Laurolitsine & $4.75-111.2$ & $14.3-35.1$ & $7.5-24.6$ & $21.8-153.6$ & $0.6-11.6$ & nd-57.3 & nd-39.2 \\
\hline Boldine & $1.38-42.2$ & $47.1-97.2$ & $6.1-19.1$ & $3.7-62.7$ & $1.0-6.4$ & $4.6-88.6$ & $8.7-123.7$ \\
\hline Reticuline & $2.81-43.9$ & $10.6-37.0$ & $7.3-36.2$ & $12.2-135.0$ & $17.3-287.0$ & $20.1-48.5$ & $3.6-542.6$ \\
\hline Laurotetanine & $0.71-165.7$ & $0.94-12.6$ & $1.2-19.7$ & $4.22-35.9$ & $6.6-180.6$ & $1.46-13-5$ & $14.6-323.4$ \\
\hline Predicentrine & nd-3.1 & nd-4.22 & nd- 2.0 & $0.54-3.58$ & $0.27-5.1$ & nd-4.2 & $1.4-44.3$ \\
\hline Isocorydine & nd-1.86 & nd-2.0 & $\mathrm{Nd}$ & nd-1.7 & nd-2.9 & nd-2.1 & $0.71-21.3$ \\
\hline Norglaucine & $0.61-19.8$ & $1.26-6.27$ & $0.38-6.4$ & $0.24-3.55$ & $0.6-75.9$ & nd-5.2 & $2.7-60.0$ \\
\hline $\mathrm{N}$-Me laurotetanine & $0.62-18.1$ & nd-6.81 & $0.36-6.6$ & $0.29-3.7$ & $1.2-170.3$ & nd-9.5 & $3.6-74.7$ \\
\hline
\end{tabular}

Results are presented as minimum and maximum concentrations found; nd: not detected.

The alkaloid concentration is highly variable, and probably plastic and dynamic during the trees' whole lifetime. Our results suggest that some of the alkaloids (particularly predicentrine and isocorydine) accumulate in the bark as the tree matures, reaching the highest concentrations in larger individuals (Table 2). In the leaves of some saplings, the noraporphines laurolitsine and laurotetanine seem to be present in significantly higher concentrations than in any leaves collected from older trees. Interestingly, laurolitsine is by far the most abundant alkaloid in the wood, at least of the smaller trees, but it is relatively unimportant in the bark irrespective of the individuals' size. Although the contents of reticuline and laurotetanine in the bark of the older individuals are highly variable, these two alkaloids are clearly dominant in young adults followed by $N$-methyllaurotetanine. All the alkaloids identified in $C$. alba are biosynthetically linked by the parallel sequences $(S)$-reticuline - [isoboldine] - N-methyllaurotetanine - boldine - predicentrine, and $(S)$-reticuline - $[(S)$ norreticuline - norisoboldine] - laurotetanine - laurolitsine - norglaucine, where the compounds in brackets have not yet been found in this tree.

Concerning the medicinal uses of $C$. alba, the very low alkaloid concentrations (less than $0.06 \%$ alkaloids in the bark used for the isolation of these compounds, and only reticuline barely exceeding $0.05 \%$ in a single bark sample) seem to indicate the unlikelihood of any relevance of these secondary metabolites to whatever pharmacological effects might be demonstrated for infusions or other preparations. In a similar vein, one may wonder if the $C$. $a l b a$ alkaloids have any ecological function at all. If the conclusion is negative, why are they there? A possible explanation is that their synthesis is an ancestral character that persists at a low rate of expression in the presence of alternative biosynthetic pathways which have proved advantageous in the evolution of the species. This recalls the now classic observation by Gottlieb that although many Brazilian Lauraceae accumulate alkaloids, in others these metabolites are replaced by more 'primitive' neolignans. ${ }^{25}$ Interestingly, other Laurales growing in or near the same areas as C. alba (the Monimiaceous Peumus boldus, and the Atherospermataceous Laurelia sempervirens and Laureliopsis philippiana) are quite rich in alkaloids.

An intriguing aspect of C. alba is that a phylogenetic analysis based on chloroplast and ribosomal genes indicates a different origin from all other South American Cryptocarya species, and a close relationship to two species from New Caledonia (C. oubatchensis and C. pluricostata).

To complicate matters further, the New Caledonian and the Chilean species do not share any obvious morphological features that appear to be derived from a common recent ancestor. Moreover, the alkaloids of $C$. ouabatchensis, though also arising from the norcoclaurine-reticuline pathway, belong to the alternatively cyclized dibenzopyrrocoline group and to the biogenetically unrelated phenanthroindolizidine family. ${ }^{26,27,28}$

The extracts of material obtained from leaves, bark, wood and roots of $C$. alba of different ages and growing in different areas of its range show a very wide variation in alkaloid distribution, although always in low concentrations. This diversity reflects an enormous spectrum influenced by many genetic, climatic and local microsite variables that would require a considerable increase in the number of individuals sampled in order to draw any firm conclusions. The results of this preliminary study on C. alba, separately examining material from a number of trees, suggest that a similar variability is likely in many other species including most of those that have been studied before on the basis of single samples, often obtained by combining several or many individual plants. In recent years we have gained access to UHPLC/MS/MS, a highly sensitive methodology. Its use, added to the continued updating of analytical protocols for the (at least tentative) analysis of secondary metabolites, opens the way to innumerable taxonomic, environmental, physiological, genetic and metabolomic studies whose results will support of the conservation and sustainable management of forest resources.

\section{ACKNOWLEDGEMENTS}

The authors thank the Fondo de Investigación del Bosque Nativo (CONAF) for grant $\mathrm{N}^{\circ}$ 055/2013, Ms. Estefanía Hugo for synthesizing norreticuline, and Dr. Edwin G. Pérez of the Facultad de Química de la Pontificia Universidad Católica de Chile for a gift of $N$-methyllaurotetanine.

\section{REFERENCES}

1. R. Fuentes-Ramirez, A. Pauchard, L. Cavieres, R. García, Forest Ecol. Manag. 261, 1003 (2011)

2. I. Benoit, Red list of Chilean Terrestrial Flora, Chilean Forest Service (CONAF), Santiago, 1989

3. C. Villagrán, L.F. Hinojosa, Rev. Chil. Hist, Nat. 70, 241 (1997)

4. N. Myers, R. Mittermeier, C. Mittermeier, G. da Fonseca, J. Kent, Nature 403, $853(2000)$

5. J. Celis-Diez, R. Bustamante, Biol. J. Linnean Soc. 84, 137 (2005)

6. G.E. Wickens, Non-forest products 5 "Edible Nuts", FAO, Rome, 1995

7. A. Hoffmann, Flora Silvestre de Chile, Zona Austral, Fundación Claudio Gay, Santiago, 1982

8. E. Gautier, Estado Actual de la Fitoquímica en Chile, Escuela de Química y Farmacia, U. de Chile, Santiago, 1956

9. M. Montes, L. Valenzuela, T. Wilkomirsky, A. Sanguinetti, D. von Baer, Ann. Pharm. Fr. 46, 41 (1988)

10. M. Avello Lorca, C. López Canales, C. Gatica Valenzuela, E. Bustos, A. Brieva Chait, E. Pastene Navarrete, M. Bittner Berner, Rev. Cubana Plant. Med. 17, 73 (2012)

11. M. Préndez, H. Peralta, Inf. Technol., 16, 17, 2012

12. B.N. Timmermann, S. Valcic, Y. Liu, G. Montenegro, Z. Naturforsch. C 50, 898 (1995)

13. M.J. Simirgiotis, Molecules, 18, 2061, (2013)

14. G. Schmeda-Hirschmann, L. Astudillo, J. Bastida, C. Codina, A. Rojas de Arias, M.E. Ferreira, A. Inchaustti, G. Yaluff, J. Pharm. Pharmacol. 53, $563(2001)$

15. D.L. Custódio, V.F. da Veiga Junior, RSC Adv. 4, 21864 (2014)

16. A. Urzúa, R. Torres, B.K. Cassels, Rev. Latinoam. Quím. 6, 102 (1975)

17. M. Asencio, B.K. Cassels, H. Speisky. Bol. Soc. Chil. Quím. 38, 331 (1993)

18. T. Kametani, M. Ihara, J. Chem. Soc. C 530 (1967)

19. R.J. Zeng, Y. Li, J.Z. Chen, G.X. Chou, Y. Gao, J.W. Shao, L. Jia, S.D. Wu, S.S. Wu, Biomed. Chromatogr. 29, 459 (2015)

20. H. Guinaudeau, M. Lebœuf, A. Cavé, Lloydia 38, 275 (1975) 
21. H. Guinaudeau, M. Lebœuf, A. Cavé, J. Nat. Prod. 42, 325 (1979)

22. H. Guinaudeau, M. Lebœuf, A. Cavé, J. Nat. Prod. 46, 761 (1983)

23. H. Guinaudeau, M. Lebœuf, A. Cavé, J. Nat. Prod. 51, 389 (1988)

24. H. Guinaudeau, M. Lebœuf, A. Cavé, J. Nat. Prod. 57, 1033 (1994)

25. O.R. Gottlieb Micromolecular Evolution, Systematics and Ecology, Springer, Berlin, 1982.
26. M. Lebœuf, A. Cavé, A. Ranaivo, Can. J. Chem. 57, 947 (1989)

27. A. Toribio, A. Bonfils, E. Delannay, E. Prost, D. Harakat, E. Henon, B. Richard, M. Litaudon, J.M. Nuzillard, J.H. Renault. Org. Lett. 8, 3825 (2006)

28. J.G. Rohwer, P.L.R. de Moraes, B. Rudolph, H. van der Werff, Phytotaxa 158, $111(2014)$ 